\title{
Psychological factors and visual fatigue in working with video display terminals
}

\author{
F Mocci, A Serra, G A Corrias
}

\begin{abstract}
Objectives-To examine the part played by psychological factors in complaints about visual health reported by banking officers who work at video display terminals (VDTs).

Methods-Out of a population of 385 bank workers, a group of 212 subjects without organic visual disturbances (as determined by opthalmological examination) who share a work environment and job duties was selected. Three questionnaires were administered to these subjects: $(a)$ the NIOSH job stress questionnaire; $(b)$ a questionnaire investigating subjective discomfort related to environmental and lighting conditions of the workplace; (c) a questionnaire on the existence of oculovisual disturbances. Correlation and multiple regression analyses were performed to examine for the presence of predictors of asthenopia.

Results-Social support, group conflict, self esteem, work satisfaction, and underuse of skills were found to be predictors of visual complaints; social support played a part also as a moderating factor in the stress and strain model; this model accounted for $30 \%$ of the variance. Subjective environmental factors, although in some cases significantly correlated with asthenopia, were not found to be strong predictors of the symptoms.

Conclusions-Some part of the complaints about visual health reported by VDT workers are likely indirect expressions of psychological discomfort related to working conditions.

(Occup Environ Med 2001;58:267-271)
\end{abstract}

Keywords: asthenopia; social support; stress

Computers have become ubiquitous in the office workplace and their use is growing. They have many advantages for inventory management, record management, complex systems control, document preparation, electronic communications, and office automation. They provide efficiency, competitive advantages, and the ability to carry out work that would be impossible or less effective without their use. Computers also provide new methods for managing work and tracking the behaviour of employees. Computerised jobs are more sedentary, require more cognitive processing and mental attention, and require less physical expenditure of energy. Yet the production demands of these jobs are often high, with constant work pressure and little decision making possibilities. Many jobs that require heavy daily computer use have been found to be stressful. $^{1-4}$

Various disturbances have been found to be related to video display terminal (VDT) work. With the spread of this type of work and the associated appearance of health complaints in workers, a vast amount of research has aimed at identifying the possible causes of the health problems associated with VDT work. ${ }^{5-7}$ There is a growing consensus that poor workstation design coupled with high workload, postural demands, and job demands can contribute to shoulder, neck, back, and wrist-hand discomfort and pain, as well as fatigue for many computer users. ${ }^{8-11}$ Improper illumination and glare, work demands, computer screen design, and task characteristics can contribute to visual discomfort. $^{12-14}$ Relations have often been found between physical disturbances and factors such as improper work organisation and job design, or with psychological factors in a broad sense.

Although there are many contributions to the scientific literature aimed at examining the part played by psychological factors in causing physical disturbances related to work at $\mathrm{VDTs}^{4}$; these studies have focused primarily on musculoskeletal ${ }^{15-17}$ or dermatological ${ }^{18}{ }^{19}$ disturbances. In the medical literature, there have been no reports of studies aimed at examining the possible role of psychological and occupational factors on asthenopia (visual discomfort or eye strain). So, our study was designed to examine the influence that different stressors such as social environment, task, and individual characteristics have on asthenopia in computer users; to study to what extent psychological stressors play a part in asthenopeic complaints, and to verify the moderating effect of social support on job stressors.

\section{Methods}

SUBJECT SELECTION

The study was performed on 385 bank workers (mean (range) age 42 (28-53) years). Men (315) made up $82 \%$ of the sample. To select a group of subjects suitable for study, the workers were evaluated for the objective conditions of their working environment and the technology used in their work. They underwent an ophthalmological examination (consisting of visual acuity at both near and far distance, and refractometry). To avoid an influence of ocular and refractive abnormalities on the subjects' reporting of visual discomfort, only those subjects identified by the ophthalmologist as presenting no conjunctival alterations or refractive errors were selected. The following 
were considered reasons for exclusion ${ }^{20}$ : presence of uncorrected hyperopia $(\geqslant+1.0 \mathrm{D}$ for people $<40$ years and $0.5 \mathrm{D}$ for people $>40$ years old), presence of uncorrected astigmatism $\left(\geqslant 1.25 \mathrm{D}\right.$ for the axes of $>30^{\circ},<60^{\circ}$ $120^{\circ}>, 150^{\circ}$; $\geqslant 0.75 \mathrm{D}$ for the axis of $\geqslant 30^{\circ}-$ $\left.60^{\circ} \geqslant, \geqslant 120^{\circ}-150^{\circ}\right)$, overcorrected myopia $(\geqslant+0.5 \mathrm{D}$ with correction).

Of these subjects (298 employees), a further selection was made of those with an equivalent working environment (noise, lighting, crowding, smoke) and who used the same technology (computers, software) in their work. This choice was made to avoid some of the principal environmental and technological confounders on the stress process. In this manner, 212 bank officers, of whom 179 were men $(85.5 \%$ of the sample with mean age 38.6) and 33 were women $(15.5 \%$ of the sample with mean age 35.2), were selected as subjects for this study.

\section{QUESTIONNAIRES}

The selected subjects were administered three questionnaires: (a) the NIOSH general job stress questionnaire, Italian version ${ }^{21}{ }^{22}$; (b) a questionnaire investigating subjective discomfort in relation to environmental conditions of the workplace; and (c) a questionnaire on the existence and extent of oculovisual disturbances (asthenopia).

From the NIOSH general job stress questionnaire the following measures were chosen

Role stressors

Role ambiguity and role conflict were measured respectively with six item and eight item scales. ${ }^{23}$ The $\alpha$ coefficients for these scales were 0.74 and 0.80 .

Social support

Caplan's 12 item scale ${ }^{24}$ was used to assess support from coworkers. The $\alpha$ coefficient was 0.84 .

Workload, underuse of skills, and work satisfaction Workload, underuse of skills, and work satisfaction were measured with Caplan's scale. ${ }^{24}$ The $\alpha$ coefficient was 0.86 .

Interpersonal conflict

Interpersonal conflict was measured with Rahim's scale. ${ }^{25}$ This scale consists of a list of 16 items that measure conflict within and between groups, and group cohesion. The $\alpha$ coefficients were $0.79,0.85$, and 0.81 , respectively.

Self esteem

Self esteem was measured with Rosemberg's scale $^{26}$; it consists of 10 items. The $\alpha$ coefficient was 0.85 .

\section{Mental workload}

Mental workload was measured with Hurrel's scale. ${ }^{27}$ The $\alpha$ coefficient was 0.75 .

Subjective discomfort related to the working environment

Subjective discomfort related to the working environment was assessed with a questionnaire which queried the subjects' sense of disturbance by noise, humidity, temperature, smoke, stale air, illumination, and crowding. Subjects were asked to respond on a four point scale $(0=$ never, $1=$ a little, $2=$ a fair amount, $3=a$ lot $)$. A final score, defined environmental discomfort, was then obtained by summing the scores for all disturbances reported.

For every subject, information was also collected about the number of hours a day at the VDT and the number of years spent performing the same work duties.

\section{Asthenopia}

Asthenopia (visual discomfort) was measured by a questionnaire which queried the presence of blurred vision, ocular soreness, itching of the eyes, blinking, heaviness of the eyes, and double vision. Subjects were instructed to respond affirmatively only if a given symptom was felt during or soon after working time. Responses were solicited on a three point scale $(0=$ never or rarely, $1=$ at least 3 days a week, $2=$ every day). The final score for the scale of asthenopia was calculated by adding the scores obtained for every ocular symptom.

\section{STATISTICAL METHODS}

We calculated Pearson's correlation coefficient to evaluate the relation between the psychological factors and asthenopia; the same relation with the environmental variables was calculated with Kendall's tau-b because of their non-normal distribution. A hierarchical regression procedure was used to assess the presence of predictors of asthenopia and eventual variables with moderating effects. ${ }^{28}$ In the first step, the main effects of age, sex, and environmental discomfort were assessed; age and sex were controlled because they may affect both the stressors exposed to, and reactions to these stressors. ${ }^{29} 30$ In the second step the psychological variables (role stressors, support from coworkers, mental workload, underuse of skills, work satisfaction, interpersonal conflict, self esteem) were inserted. To verify a moderating effect of colleague support on the relation between psychological stressors and asthenopia, in the third step the cross product terms between each stressor and support from coworkers were entered.

\section{Results}

Sixty eight of the subjects (52 men and 16 women, $31.9 \%$ of the sample) queried were found to have asthenopia as defined by our criteria, reporting at least one of the symptoms of asthenopia during or soon after the work shift three or more times a week. Twenty nine subjects $(13.6 \%$ of the sample, 20 men and nine women) met the criterion of strongly asthenopic, reporting at least one of the symptoms of asthenopia every day.

Correlations between the presence of asthenopia and the various psychological factors or environmental discomfort factors investigated are presented in tables 1 and 2 .

Among the psychological factors (table 1), physical workload was the only factor not significantly correlated with asthenopia, 
Table 1 Descriptive statistics and Pearson's correlation coefficients among psychological variables and asthenopia

\begin{tabular}{|c|c|c|c|c|c|c|c|c|c|c|c|}
\hline & Mean & $S D$ & 1 & 2 & 3 & 4 & 5 & 6 & 7 & 8 & 9 \\
\hline 1 Group conflict & 2.98 & 0.85 & & & & & & & & & \\
\hline 2 Coworker support & 1.75 & 0.80 & $-0.28^{\star \star}$ & - & & & & & & & \\
\hline 3 Physical workload & 4.28 & 0.64 & $0.23^{\star}$ & $-0.23^{\star \star}$ & - & & & & & & \\
\hline 4 Underuse of skills & 2.34 & 0.76 & 0.05 & $-0.40^{\star \star}$ & $0.22^{\star}$ & - & & & & & \\
\hline 5 Mental workload & 3.15 & 0.32 & 0.06 & -0.08 & -0.06 & $0.17^{\star}$ & & & & & \\
\hline 6 Self esteem & 1.68 & 0.73 & $-0.25^{\star \star}$ & $0.20^{\star}$ & $-0.23^{\star}$ & $-0.19^{\star}$ & -0.12 & & & & \\
\hline 7 Work satisfaction & 3.04 & 0.35 & $-0.27^{\star \star}$ & 0.10 & $-0.31^{\star \star}$ & -0.08 & -0.04 & $0.18^{\star}$ & & & \\
\hline 8 Role conflict & 5.42 & 1.06 & $0.21^{\star}$ & $-0.25^{\star}$ & 0.04 & $0.26^{\star \star}$ & $0.20^{\star}$ & 0.13 & -0.14 & & \\
\hline 9 Role ambiguity & 1.65 & 0.52 & $0.28^{\star \star}$ & -0.07 & 0.15 & 0.18 & 0.10 & 0.09 & -0.10 & 0.10 & \\
\hline 10 Asthenopia & 0.41 & 0.84 & $0.30^{\star \star}$ & $-0.32^{\star \star}$ & 0.10 & $0.23^{\star}$ & $0.25^{\star \star}$ & $-0.23^{\star \star}$ & $-0.24^{\star \star}$ & $0.29^{\star \star}$ & $0.20^{\star}$ \\
\hline
\end{tabular}

${ }^{\star} \mathrm{p}<0.05 ;{ }^{\star \star} \mathrm{p}<0.01$ two tailed.

whereas among environmental factors (table 2 ), asthenopia was found to be significantly positively correlated with the presence of discomfort relative to noise and smoke. It is interesting to note that lighting conditions were not correlated with eye discomfort.

No correlation (table 3) was found between asthenopia and number of hours of work a day at the VDT or number of years spent performing the same work duties. Asthenopia was correlated with age, sex, and environmental discomfort (total score).

As well as the correlations between psychological or environmental factors with asthenopia, numerous significant correlations were also found among the various psychological stress variables and among reports of distur-

Table 2 Kendall's correlation coefficients among different environmental variables and asthenopia

\begin{tabular}{llllllll}
\hline Variables & 1 & 2 & 3 & 4 & 5 & 6 & 7 \\
\hline 1 Noise & - & & & & & & \\
2 Crowding & $0.23^{\star}$ & & & & & & \\
3 Lighting & 0.00 & $0.33^{\star \star}$ & & & & & \\
4 Smoke & $0.24^{\star \star}$ & 0.03 & $0.50^{\star \star}$ & & & & \\
5 Stale air & $0.23^{\star \star}$ & $0.27^{\star \star}$ & $0.33^{\star \star}$ & $0.28^{\star \star}$ & & & \\
6 Temperature & 0.00 & 0.02 & 0.05 & 0.00 & 0.08 & & \\
7 Dampness & 0.06 & 0.09 & 0.12 & 0.01 & 0.03 & 0.08 & \multirow{2}{*}{0.11} \\
8 Asthenopia & $0.27^{\star \star}$ & 0.012 & 0.09 & $0.28^{\star \star}$ & 0.14 & 0.06 & 0.14 \\
\hline
\end{tabular}

${ }^{\star} \mathrm{p}<0.05 ;{ }^{\star \star} \mathrm{p}<0.01$ two tailed.

Table 3 Pearson's correlation coefficients between asthenopia, environmental discomfort, and other variables

\begin{tabular}{llllll}
\hline Variables & 1 & 2 & 3 & 4 & 5 \\
\hline 1 Hours/day at VDT & - & & & & \\
2 Years at VDT & 0.15 & & & & \\
3 Age & 0.12 & $0.40^{\star \star}$ & & & - \\
4 Sex & 0.07 & 0.04 & 0.04 & 0.09 & - \\
5 Environmental discomfort & 0.12 & 0.06 & 0.14 & $0.23^{\star}$ \\
6 Asthenopia & 0.18 & 0.05 & $0.45^{\star \star}$ & $0.35^{\star \star}$ & 0.06 \\
\hline
\end{tabular}

${ }^{\star} \mathrm{p}<0.05 ;{ }^{\star \star} \mathrm{p}<0.01$ two tailed.

Table 4 Hierarchical regressions of age, sex, environmental discomfort, and psychological variables on asthenopia (only variables with $p<0.05$ are reported)

\begin{tabular}{|c|c|c|c|c|c|c|}
\hline & \multicolumn{2}{|c|}{$\begin{array}{l}\text { Unstandardised } \\
\text { coefficients }\end{array}$} & \multirow{2}{*}{$\begin{array}{l}\text { Standardised } \\
\text { coefficient } \beta\end{array}$} & \multirow[b]{2}{*}{$p$ Value } & \multirow[b]{2}{*}{$R^{2}$} & \multirow[b]{2}{*}{ Adjusted $R^{2}$} \\
\hline & $\beta$ & SEM & & & & \\
\hline \multicolumn{7}{|l|}{ Step 1: } \\
\hline Environmental discomfort & 0.812 & 0.366 & 0.244 & 0.02 & 0.059 & 0.04 \\
\hline Step 2: & & & & & 0.33 & 0.28 \\
\hline Self esteem & -0.328 & 0.128 & -0.279 & 0.012 & & \\
\hline Group conflict & 0.394 & 0.117 & 0.335 & 0.001 & & \\
\hline Work satisfaction & -0.715 & 0.242 & 0.306 & 0.004 & & \\
\hline Underuse of skills & 0.181 & 0.073 & 0.313 & 0.015 & & \\
\hline Coworker support & -0.507 & 0.158 & -0.344 & 0.000 & & \\
\hline Step 3: & & & & & 0.34 & 0.30 \\
\hline $\begin{array}{l}\text { Coworker support } \times \text { group } \\
\text { conflict }\end{array}$ & -0.188 & 0.051 & -0.523 & 0.000 & & \\
\hline
\end{tabular}

bance by various environmental factors (tables 1 and 2).

Multiple regression analysis was performed to examine the presence of predictors of asthenopia. As shown in table 4, in the first step, environmental discomfort was found to account for $4 \%$ of the variance in the reporting of symptoms of asthenopia, whereas age and sex were not found to have a significant influence.

In the second step of the regression analysis, when the psychological aspects of work with VDTs were entered, self esteem, group conflict, work satisfaction, underuse of skills, and coworker support were found to be significant predictors of visual complaints, and the model accounted for $28 \%$ of the variance. Role stressors and mental workload did not reach significance $(F<0.05)$ and were removed from the model.

In the third step the presence of a moderator effect of support from coworkers on the other stressors was verified. An analysis of cross product terms showed that coworker support had a moderating effect on the predictive influence of group conflict on asthenopia, whereas the other cross product terms had no significant influence and thus were removed. When this moderator effect was considered, the final model was found to account for $30 \%$ of the variance in reporting of asthenopia.

\section{Discussion}

It has to be recognised that work stress can produce both physical and emotional complaints. Job demands-physical and psychological-influence the severity and frequency of health complaints of VDT operators. The expression of these complaints may be exacerbated by perceived high job demands, boring or repetitive job activity, and poor support from colleagues and supervisors. Previous investigations on visual health complaints by VDT operators have shown relations between the presence of asthenopia and environmental variables, including lighting characteristics of the workplace, ${ }^{5}$ and physical variables - such as the refractive index of the subjects. ${ }^{14}$ The present study verifies a role of psychological factors in asthenopia.

Certainly, there exists a difficulty at the medical level of defining and measuring asthenopia, ${ }^{31}$ this being identified as the more or less striking presence of any of several different disturbances including a sensation of heaviness of the eyes, conjunctival redness, a subjective per- 
ception of tiredness, dry eyes due to insufficient production of tears, and sudden phenomena of double vision or clouding of vision. Essentially, we are dealing with an ophthalmological clinical picture, the distinguishing features of which are still imprecise and not well measurable. This aspect has generated many investigations in which the prevalence of the disturbance found in different populations seems extremely variable. This variability, expected on the basis of differing working conditions and oculovisual characteristics of VDT operators, is certainly augmented as a result of the imprecise definition of asthenopia. In our work, we adopted a strict criterion, considering visual disturbances to be indicative of asthenopia only if reported to occur at least three times a week, during or shortly after the end of work at a VDT.

The prevalence of the disturbance as determined by our study (around 32\%) was less than that described in other reports. ${ }^{5}$ This discrepancy can be explained by several factors: firstly, by the greater selectivity of the subjective measure used to identify asthenopia in our study; secondly, by the good optometric conditions of the subjects admitted into the study; and thirdly, by the workplace characteristics of our sample, typical of banks and characterised by particular attention to ergonomic construction of the working environment, in particular of lighting, workers' posture, and air conditioning.

Precisely these workplace characteristics might also explain the unexpected lack of correlation between illumination and asthenopia, which, as already stated, is amply documented in the literature. Even one other recent study has found no significant influence of the level of surrounding luminance on asthenopic symptoms. ${ }^{32}$ The questions on environmental discomfort and those of asthenopia were, furthermore, administered together, in the same sitting. This might have been expected to increase the correlations between these measures. Instead, these were negligible to low, suggesting that in our study, some of the environmental discomfort factors (lighting, temperature, stale air, dampness) had no effect on asthenopia. The same considerations were supported by the multivariate analysis, where environmental factors reported by the subjects as sources of disturbance were found to have little effect on the presence of asthenopia.

Our investigation was conducted on a selected population of subjects with superimposable environmental working conditions and work duties. All the subjects were without oculovisual abnormalities. This selection was made to reduce or exclude the presence of asthenopeic disturbances resulting from environmental, and ergonomic factors, or refractive conditions of the subject. In these conditions, the study showed clearly that several psychological factors were predictors of visual complaints. The model elaborated in the regression analysis accounted for $30 \%$ of the variance in the reporting of visual complaints.

The roles of the various psychological factors studied here are different. Although group conflict and underuse of skills are true stressors, coworker support (which refers to the provision and receipt of tangible goods, services, and benefits - such as informal encouragement and reassurance), and self esteem are buffers that have been found in previous research to act as moderators of the weight of stressors on health complaints. The investigation confirmed this expectation; coworker support showed both a direct role in the regression terms and a role as a moderator in the relation between group conflict and health complaints. Consistent with the findings of Hagihara et al, ${ }^{33}$ the same type of moderating role of colleague support was not found on other variablessuch as underuse of skills.

The factor mental workload was particularly correlated with work at VDTs, and the correlation between mental but not physical workload and asthenopia was expected. (The physical and mental demands required by jobs that use computers are very different from noncomputerised office or blue collar jobs; usually computerised jobs are more sedentary, require more cognitive processing and mental attention, and require less physical expenditure of energy.) Although not found by our regression analysis to be a predictor of asthenopia, mental workload has been amply shown in past research to have a role as a stressor correlated with physical disturbances. ${ }^{44} 35$

It does not seem possible to directly attribute disturbance to the other variables, as these are more connected to the social structure of work than to the duties required. The asthenopia in this case seems to be the indirect expression of lack of wellbeing at work, poor support from colleagues, or conflicts with colleagues.

Some limitations of our work must be pointed out. We made use only of self reported measures in the evaluation of environmental discomfort, visual discomfort, and occupational stressors. As is known, these measures, which are certainly the most commonly used in research, introduce several problems: there is evidence that their use can lead to an overestimate of the correlation between stressor and dysfunctioning. Furthermore, they make possible the interference of a third variable that influences both the dependent and independent variables (in our study this occurred in the case of support from coworkers).

Finally, the use of self reports of both job stressors and strains (the asthenopia in this study was read as an indirect expression of strain) in a study increases the potential for conceptual overlap in the measures, by which the independent and dependent variable measures, in essence, assess largely the same construct.

A possible solution to this problem would be to introduce, in future research, some more objective measures of visual disturbances and the various stressors present in the work environment. This approach, which has been used in research on analogous problems, ${ }^{736}$ seems, despite its own limitations, to be the most promising. 


\section{Conclusion}

This study supports the idea that the aetiological basis of symptoms of visual discomfort symptoms among VDT workers includes psychological factors, and that the interaction between such factors might be important in the understanding of visual complaints by VDT workers. In our opinion, furthermore, the analysis of the influence of psychological factors on asthenopia increases the possibility of preventive interventions in occupational medicine aimed at creating conditions of wellbeing, and thus the reduction of disturbances.

Future research should be aimed at investigating the relations between various stressors, and at verifying with field studies some of the hypotheses that have been confirmed in the present work (for example the role of colleague support as a moderating factor in the perception of stress), but which still lack confirmation by experimental studies. Measures to stimulate colleagues to support one another could reduce the effect of work related stressors and confirm the theoretical studies on stress conducted to date.

We gratefully acknowledge Shira Rubinstein for generous help with preparation of the manuscript.

1 Smith MJ. Health issues in VDT work. In: Bennet J, Case D, Sandlin J, et al. eds. Visual display terminals. New Jersey: Prentice Hall, 1984:193-228.

2 Dainoff MJ, Happ A, Crane P. Visual fatigue and occupational stress in VDT operators. Hum Factor 1981;23:421-38

3 Carajon P. Job design and job stress in office workers. Ergonomics 1993;5:463-77.

4 Smith MJ. Psychological aspects of working with video display terminals (VDTs) and employee physical and mental health. Ergonomics 1997;40:1002-15.

5 Bergqvist UO, Knave BG. Eye discomfort and work with visual display terminals. Scand $\mathcal{f}$ Work Environ Health 1994;20:27-33.

6 Thomson WD. Eye problems and visual display terminals: the facts and the fallacies. Ophthalmic Physiol Opt 1998;18: 111-19.

7 Aaras A, Horgen G, Bjorset HH, et al. Musculoskeletal, visual and psychological stress in VDU operators before and after multidisciplinary ergonomic interventions. $A p p$ Ergon 1998;29:335-54

8 Kietrys DM, McClure PW, Fitzgerald GK. The relationship between head and neck posture and VDT screen height in keyboard operators. Phys Ther 1998;78:395-403.

9 Marcus M, Gerr F. Upper extremity musculoskeletal symptoms among female office workers: associations with video display terminal use and occupational psychosocial stressors. Am F Ind Med 1996;29:161-70.

10 Ziefle M. Effects of display resolution on visual performance. Hum Factors 1998:40:554-68.

11 Saito S, Miyao M, Kondo T, et al. Ergonomic evaluation of working posture of VDT operation using personal computer with flat panel display. Ind Health 1997;35:264-70.

12 Läubli T, Hunting W, Grandjean E. Postural and visual loads at VDT workplace. Lighting conditions and visual impairment. Ergonomics 1981;24:933-44.
13 Jaschinski W, Heuer H, Kylian H. Preferred position of visual displays relative to the eyes: a field study of visual train and individual differences. Ergonomics 1998;41: 1034-49.

14 Nakaishi H, Yamada Y. Abnormal tear dynamics and symptoms of eyestrain in operators of visual display terminals. Occup Environ Med 1999;56:6-9.

15 Faucett J, Rempel D. VDT-related musculoskeletal symptoms: interactions between work posture and psychological work factors. Am f Ind Med 1994;26:597-612.

16 Marcus M, Gerr F. Upper extremity musculoskeletal symptoms among female office workers: associations with video display terminal use and occupational psychological display terminal use and occupational
stressors. Am f Ind Med 1996;29:161-70.

17 Ong CN, Chia SE, Jeyaratnam J, et al. Musculoskeletal disorders among operators of visual display terminals [commentary]. Scand $\mathcal{F}$ Work Environ Health 1995;21:60-4.

8 Stenberg B, Eriksson N, Mild KH, et al. Facial skin symptoms in visual display terminal (VDT) workers. A case-referent study of personal, psychological, buildingand VDT-related risk indicators. Int $\mathcal{F}$ Epidemiol 1995;24: 796-803.

19 Eriksson N, Hoog J, Sandstrom M, et al. Facial skin symptoms in office workers. A 5 year follow-up study. $\mathcal{F}$ Occup Environ Med 1997;39:108-18.

20 Nakaishi H, Miyao M. Establishment of an expert system for visual display terminals (VDT) workers' periodic eye checkups. In:Anzai Y, Ogawa K, Mori H, ed. Advances in human factors/ergonomics 20B. Amsterdam: Elsevier, 1995: 599-604.

21 Hurrell JJ Jr, McLaney MA. Exposure to job stress: a new psychometric instrument. Scand $\mathcal{F}$ Work Environ Health 1988;14(suppl 1):27-8

22 Mocci F. Valutazione psicometrica dello stress: proposta della versione italiana del NIOSH general job stress questionnaire. Archivio di Scienze del Lavoro 1994;10:31319.

23 Rizzo JR, House RJ, Lirtzman SI. Role conflict and ambiguity in complex organizations. Adm Sci O 1970;15:150-63.

24 Caplan RD, Cobb S, French JRP Jr, et al. Fob demands and worker health. Cincinnati: HEW Publication, National Institute for Occupational Safety and Health, 1975;75160.

25 Rahim MA. Measurement of organizational conflict. $f$ Gen Psychol 1983;109:189-99.

26 Rosenberg M. Society and the adolescent self image. Princeton, NJ: Princeton University Press, 1965.

27 Hurrel JJ, Smith MJ, Burg JR, et al. Fob demands and worker health in machine paced letter sorting. Cincinnati, Ohio: National Institute for Occupational Safety and Health, 1985

28 Cohen J, Cohen P. Applied multiple regression/correlation for the behavioural sciences, 2nd ed. Hillsdale, NJ: Erlbaum, 1983.

29 Mayes BT, Barton ME, Ganster DC. An exploration of the moderating effect of age on job stressors-employee strain relationship. Fournal of Social Behavior and Personality 1991; 6:289-308

30 Jick TD, Mitz LF. Sex differences in work stress. Acad Manag Rew 1985;10:408-20.

31 Chi CF, Lin FT. A comparison of seven visual fatigue assessment techniques in three data-acquisition VDT assessment techniques in three

32 Wolska A, Switula M. Luminance of the surround and visual fatigue of VDT operators. Int $\mathcal{f}$ Occup Saf Ergon 1999;5:553-81.

33 Hagihara A, Tarumi K, Miller AS. Social support at work as a buffer of work stress: strain relationship: a signal detection approach. Stress Medicine 1998;14:75-81.

34 Saito K. Measurement of fatigue in industries. Ind Health 1999;37:134-42.

35 Kurimori S, Kakizaki T. Evaluation of work stress using psychological and physiological measures of mental activity in a paced calculating task. Ind Health 1995;33:7-22.

36 Gerr F, Marcus M, Ortiz DJ. Methodological limitations in the study of video display terminal use and upper extremity musculoskeletal disorders. Am f Ind Med 1996;29:649-56.

\section{Rejected manuscripts}

Authors whose submitted articles are rejected will be advised of the decision and one copy of the article, together with any reviewer's comments, will be returned to them. The fournal will destroy remaining copies of the article but correspondence and reviewers' comments will be kept. 